\title{
A Design Approach on the Use of Lightweight Filling Materials for Construction of an Aircraft Deicing Station at a Critical Soil Site: a Case Study
}

\author{
F. D’Amico ${ }^{1}$, L. Bianchini Ciampoli ${ }^{1}$, V. Gagliardi ${ }^{1}$ and F. Tosti ${ }^{2}$ \\ ${ }^{1}$ Department of Engineering, Roma Tre University, Via Vito Volterra 62, 00146, \\ Rome, Italy; email: fabrizio.damico@uniroma3.it; \\ luca.bianchiniciampoli@uniroma3.it; valerio.gagliardi@uniroma3.it \\ ${ }^{2}$ School of Computing and Engineering, University of West London (UWL), St Mary's \\ Road, Ealing, W5 5RF, London, UK e-mail: Fabio.Tosti@uwl.ac.uk
}

\begin{abstract}
Deicing and anti-icing operations are frequently carried out on aircrafts at their current parking stand after completion of ground operations. Use of individual stands can be often challenging as this may also considerably affect operations, especially in highlytrafficked airports at winter-critical areas. Hence, a lack of or an incorrect location of these stations may have tremendous economic and operational impact.

This research reports a multi-stage design method for construction of a $29.000-\mathrm{m}^{2}$ deicing station in a critical soil site. The main aim of the project is to identify sustainable interventions to avoid short- and long-term economic, environmental and operational issues. An assessment based on the use of fundamental geotechnical parameters is first implemented to create thematic maps of the identified construction area, followed by a comparative analysis of potential intervention scenarios. A combination of lightweight filling and advanced materials has been proposed to ensure homogeneity and suitable bearing capacity of the laying ground.
\end{abstract}

Keywords: airport apron, deicing station, lightweight filling materials; expanded clay; multi-stage design method.

\section{INTRODUCTION}

Deicing is configured as the operation of ice removal from critical sections of an aircraft before taking-off manoeuvers. This operation is crucial in airports located in winter-critical areas, as it is known that ice and frozen contaminants can settle on the surface of the aircraft, especially on the wings. This might potentially create critical control surfaces that can eventually turn into rough and uneven. Hence, presence of ice or snow on the surface of an aircraft can disrupt regular smooth airflow and affect the ability of wings to trigger lift and increasing drag. It is evident how this occurrence can significantly increase the risk of accidents and potentially lead to dramatic events (Federal Aviation Administration, 2013).

Dicing and anti-icing operations are frequently conducted on aircrafts at their regular parking stand after completion of ground operations. Despite of this, these activities can significantly affect airport operations, depending on the specific 
requirements (Federal Aviation Administration, 2017). Delays on standard routine operations carried out in airport aprons are therefore expected. This is especially true for highly-trafficked airports or when peaks of traffic are encountered, thereby resulting in flight delays and economic losses.

To this effect, individual parking stands are mostly required to allow dedicated trucks to manoeuver around the aircraft and perform required deicing operations. Within this context, dedicated deicing aprons are normally located at airports in winter-critical areas to meet high safety standards for prevention of accidents.

\section{STATEMENT OF THE PROBLEM}

A lack of or an incorrect location of deicing stations may have tremendous economic and operational impact. Location of deicing aprons is crucial to minimize taxiing time between start of treatment operations and take off, as well as to avoid the effect of potential changes in weather conditions when aircrafts have extra-long taxiway routes. Nevertheless, this can be a difficult task when the in-situ soil is not suitable for construction purposes, i.e., when soil quality indexes are outside permitted ranges/values from standards.

Within this context, it is important to identify new avenues to regulate design of deicing stations in critical soil sites. Solutions may be straightforward (e.g., availability of alternative areas for infrastructure location or alternative filling materials to replace unsuitable soil masses), whereas important technical, environmental and economic constraints may sometimes make the whole process as more complex and time-consuming (Marradi et al., 2012).

\section{AIM \& OBJECTIVES}

The primary aim of the project is to identify sustainable interventions for construction of an airport deicing station in order to avoid short- and long-term economic, environmental and operational issues on the infrastructure.

To achieve this aim, the main objective is to develop an innovative multistage design approach based on the assessment of fundamental geotechnical parameters and use of lightweight filling materials. Another objective of the paper is to propose a new pavement layout more suitable for an airport apron.

\section{METHODOLOGY}

The proposed multi-stage design approach is based on i) use of fundamental geotechnical parameters, ii) creation of parameter-based thematic maps, iii) 
comparative analysis of potential intervention scenarios, and iv) identification of the most suitable solution under optimal "cost-benefits" criteria. This method is applied for construction design of a deicing station area in a critical soil site. To this effect, use of innovative lightweight filling and advanced materials is accounted to identify the most suitable solution in terms of homogeneity and bearing capacity of the laying ground.

\section{THE STUDY CASE: “GUGLIELMO MARCONI" INTERNATIONAL AIRPORT}

\section{The Airport}

The deicing station under design is planned to be located at the International Airport "Guglielmo Marconi" in Bologna, Italy.

According to the Italian Civil Aviation Authority (ENAC, 2017), the airport was ranked sixth among the national airports in terms of yearly commercial traffic operations (more than 67000 operations in 2017), and eighth as per yearly carried passengers (more than 8 million passengers in 2017).

The airport is composed of a single $36000-\mathrm{m}^{2}$ terminal area with 24 departure gates. The airport has one main runway, "NW-SE"-oriented, of dimensions $2803 \mathrm{~m}$ (length) $\times 45 \mathrm{~m}$ (width). Runway is served by a parallel taxiway, having both a flexible pavement structure.

Climate of the geographic area is classified as temperate-humid and featured by hot and humid summers and mildly cold winters. To this effect, an average yearly amount of 49 days with temperature lower than $0^{\circ} \mathrm{C}$ is reported by the Metereological Service from the Italian Air Force (Servizio Metereologico Aeronautica Militare, 2010). In view of this, a new deicing station is proposed to meet the airport operation requirements.

\section{The Construction Site Area}

According to the development master plan of the airport, the deicing station is planned to be located in a $29000-\mathrm{m}^{2}$ area at south-east of the current taxiway (Fig. 1(a)). The area is close to the starting section of the runway (Fig. 1(b)) and it was identified to minimise the taxiing time between deicing and take-off operations. 

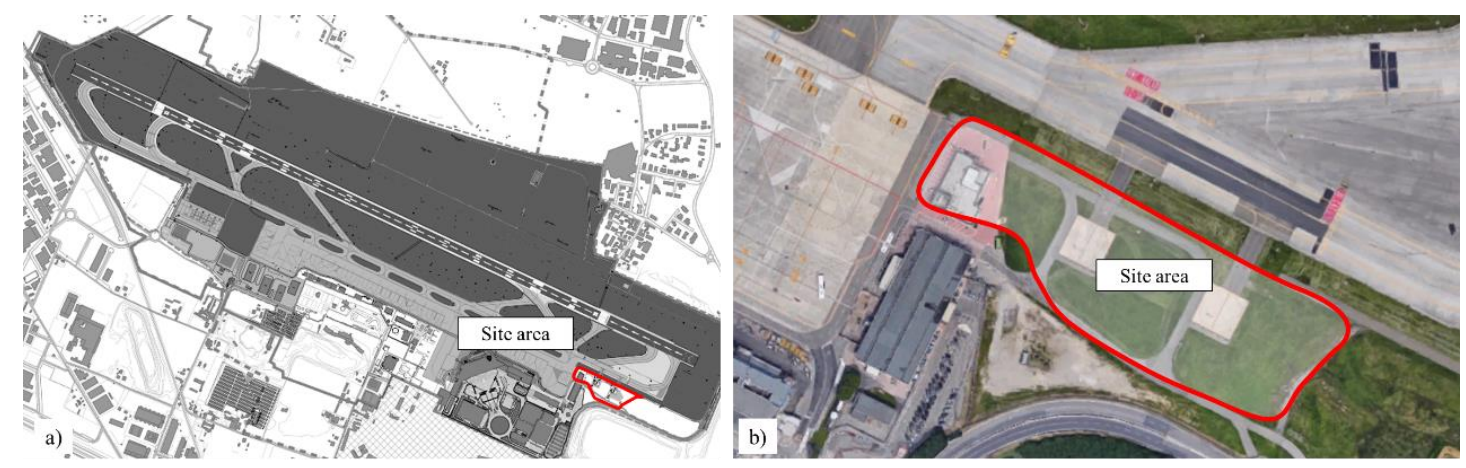

Figure 1. Location of the site area in the airport.

Soil in the area has weak bearing capacity, as the site was used as a construction dump deposit in the past years. The geology of the area is made of vertical and horizontal layering of both fine and coarse deposits. Soil lithology shows a sandygravelly covered of a variable layer of fine material.

The existing ground level profile is variable across the identified area with respect to the design level. This implies use of embankments and road cuts.

\section{Preliminary Surveys}

To assess the soil response against potential modifications caused by the construction of a deicing apron, the following steps are required:

- investigation of the soil performance properties at the construction site area;

- evaluation of the soil grain size: mapping of the loop to $75 \mu$;

- estimation of Atterberg Limits;

- mapping the thickness of the compressible layer.

The above information can be achieved by means of in-situ and laboratory tests complemented by geological surveys.

The first stage of the project is based on the analysis of the performance properties of the soil, through the evaluation of geotechnical parameters and indices of compressibility and plasticity. To this purpose, the i) Atterberg limits (plastic limit $w_{p}$, and liquid limit $w_{l}$ ) and the ii) plastic index $\left(I_{p}\right)$ are used to identify areas with critical water contents as well as to assess potential plastic and compressible behaviours of the in-situ soil.

Trends of the two indicators are relatively-well comparable. A progressive decay of analysed geotechnical parameters is observed towards the S-E direction. In more detail, values of $w_{l}$ and $I_{p}$ ranging between $40 \div 50$, and $20 \div 30$, respectively, were observed in the S-E area of the site, as it is shown in Fig. 2. 


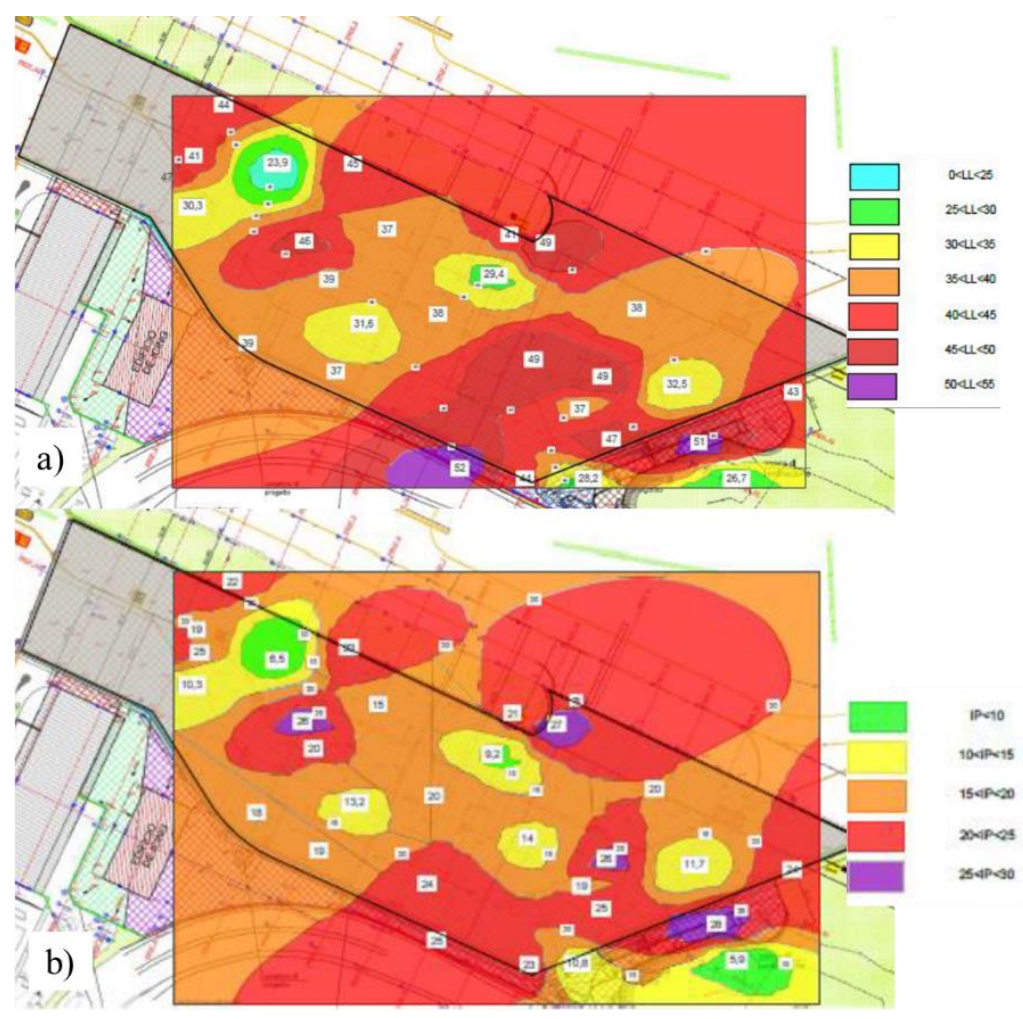

Figure 2. Thematic maps of the distribution of: a) Liquid Limit $w_{l}$, and b) Plastic Index $I_{p}$. across the construction design area.

Non-plastic (i.e., $I_{p}<10$ in Fig. 2(a)) soil outcomes from tests were only found in a small spot located in the N-W corner of the site. Non-compressible conditions of the soil (i.e., $w_{l}<40$ in Fig. 2(b)) were the most widespread across the whole area.

Fig. 3 shows distribution of areas within the construction site expected to show plastic and compressible behaviour. It is evident that the overall behaviour across the entire area is mostly plastic, whereas compressibility is moreover located in the SE region of the site.

Finally, the thickness of the compressible layer was investigated, in order to identify potential soil subsidence caused by the weight of the embankments, the pavement structure and the parking loads. Outcomes from this assessment are reported in Fig. 4, where a thickness ranging between $0 \mathrm{~m}$ and $8 \mathrm{~m}$ is found. In more detail, a thickness of the compressible layer higher than $4 \mathrm{~m}$ is mostly identified.

By cross-matching the above information with the location of the carryover embankment, it is possible to calculate the differential subsidence of the subgrade under design loading conditions. To that effect, the Terzaghi's method (Barends, 2011) is used for calculation purposes. Results have shown that it is expected to observe a maximum subsidence of $7 \mathrm{~cm}$, matching the spot area with maximum compressible thickness in Fig. 4. 


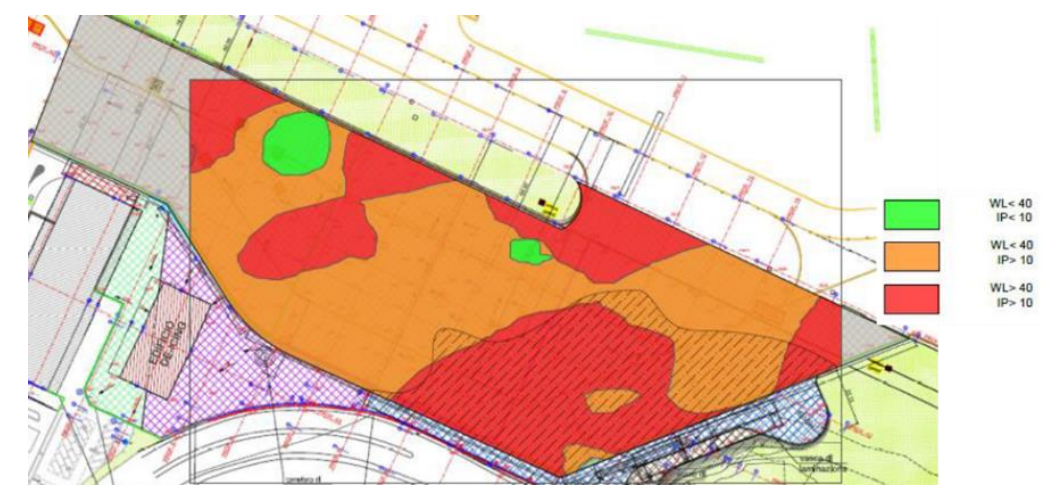

Figure 3. Thematic maps of plastic and compressible behaviour of the soil within the site area.

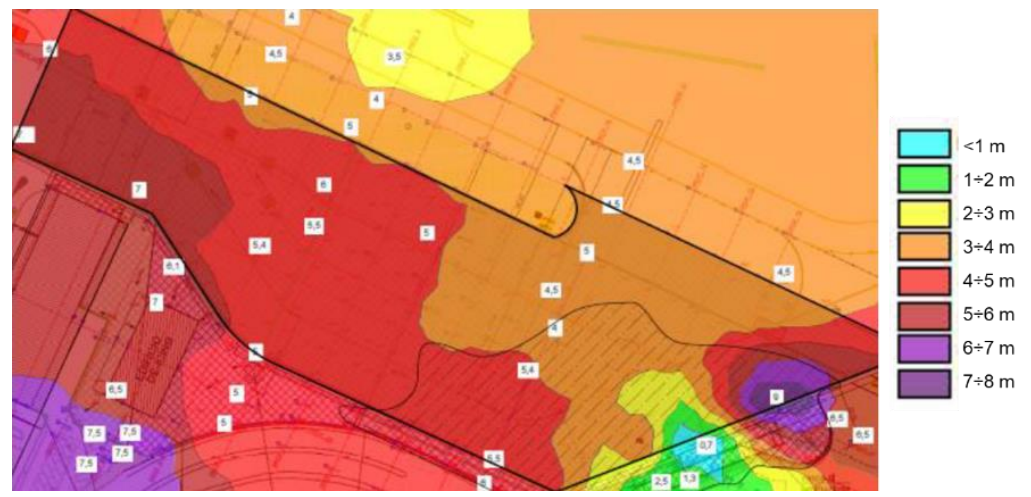

Figure 4. Thematic map of thickness of the compressible layer over the construction site, with area interested by the realisation of the embankment overlapped in black dashed line.

\section{The Pavement Layout}

A pavement layout suitable to sustain parking loads from aircrafts during deicing operations is here proposed. Pavement design is performed by means of the FAARFIELD (Federal Aviation Administration, 2016) software with the following input data:

- definition of stratigraphy and spacing between longitudinal and transverse joints;

- mechanical characteristics of the load-bearing material (CBR, or K);

- characteristics of the concrete (tensile strength due to bending, E);

- traffic data in terms of amount of annual take-off manoeuvres and maximum take-off weight (annual departures and percent annual growth).

A reference service-life of 20 years is assumed for the pavement. Boeing 767 is the reference aircraft used for design purposes and assumption of homogeneous load distribution between the 4 wheels of each trolley of the aircraft is considered. In this regard, load for a single wheel is assumed as approximately 20 tons. 
The Theory of Westergard (Yoder et al., 1975; Delatte, 2014) is used to verify thermal and load stresses, as these are a function of a wide range of parameters.

Stress in the most unfavourable conditions of load and temperature is verified to be less than $80-90 \%$ of the bending stress in concrete. Following the assumption about the layer thicknesses, the overall pavement layout reported in Fig. 5 is determined according to the cumulative damage factor (Federal Aviation Administration, 2016).

The designed rigid pavement structure is eventually cross-checked against thermic and load-related stress using the HIPERPAV III software (Federal Highway Administration, 2009). This allows verification of the absence of potential early cracking conditions. As a result, a slab with a dimension of $4 \mathrm{~m}$ is identified for the project.

\section{INTERVENTION DESIGN}

Innovative techniques are here investigated with the aim of lightening the weight of the embankments needed to sustain the designed pavement structure. These embankments are expected to be subject to subsidence in view of the high plasticity of the in-situ soil. Thereby, a specific task of the intervention is to directly counteract the source of subsidence, i.e., the weight of the pavement structure and loads from parked aircrafts, by using lightened materials (Vaslestad et al., 1993; Budhu, 2010).

In more detail, the reduced weight of lightweight embankments is capable to exert a lower stress state on the supporting ground. Such reduced stress state can be also completely removed in case the in-situ soil is replaced by lightweight filling.

Among the available lightweight construction materials, the lightweight expanded clay aggregate, or expanded clay, is one of the most employed (Marradi et al., 2012). Specifically, this is a lightweight aggregate made by heating clay at around $1200{ }^{\circ} \mathrm{C}$ in a rotary kiln. The yielding gases expand the clay by thousands of small bubbles that form during heating and create a honeycomb structure.

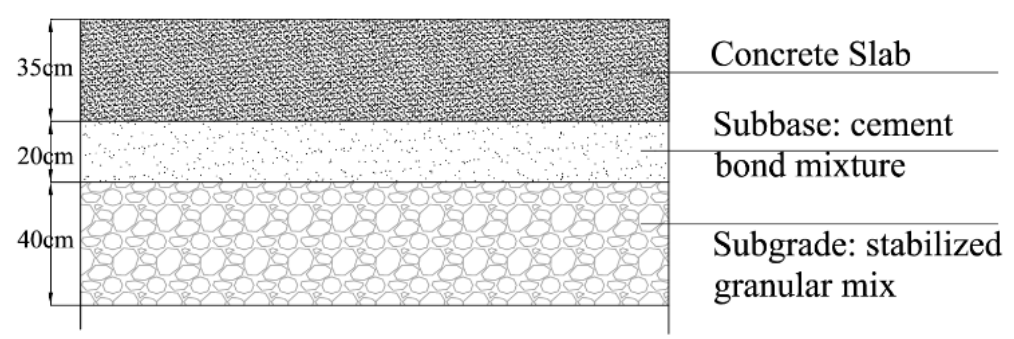

Figure 5. Scheme of pavement layout assumed for construction design of the deicing station. 
In this project, expanded clay embankments are used to replace the plastic in situ soil and avoid differential subsidence in the area. This is achieved by reducing the weight exerted by the pavement structure on areas with subgrade of weak bearing capacity.

An innovative design approach is therefore proposed and a combination of lightweight filling and advanced materials is used. To this effect, the aforementioned preliminary surveys allowed to estimate the amount of compensating lightweight filling material, according to the height of the designed embankments. This is a crucial information to ensure suitable homogeneity and bearing capacity of the laying ground.

\section{Intervention Scenario 1}

The intervention assumed in this scenario is composed of a regular arrangement of layers of different materials. Use of expanded clays provides that material is spread throughout layers of thickness not exceeding $100 \mathrm{~cm}$, up to the required height of the filling. Nonetheless, a $25 \mathrm{~cm}$ layer of quarry granular mix is here considered to be laid every $75 \mathrm{~cm}$ of lightweight filling. This is in order to optimise compaction operations, as rollers cannot operate in direct contact with the expanded clay layer.

At each interface between the above layers, a non-woven fabric geosynthetic layer is laid to avoid potential pollution of the expanded clay layer with fines as well as to allow permeability to water.

Fig. 6(a) shows the designed layering for the intervention scenario 1 . According to the expected height of the embankment, a certain volume of in-situ compressible soil was selected to be excavated and replaced with lightweight expanded clay. This compensated the overloading due by the embankment construction.

From the application of the Terzaghi equation to the specific areas interested by embankments, it was possible to back-calculate the depth of excavations required to compensate the load of the pavement structure. A map of excavation depth over the site area is shown in Fig. 6(b). To this effect, average and maximum depths of the excavations were found to be $2.7 \mathrm{~m}$ and $4.2 \mathrm{~m}$, respectively.

\section{Intervention Scenario 2}

In order to reduce the economic and environmental impact of the above solution, and thereby to minimize the volume of lightweight filling material, a further intervention scenario is here proposed. 

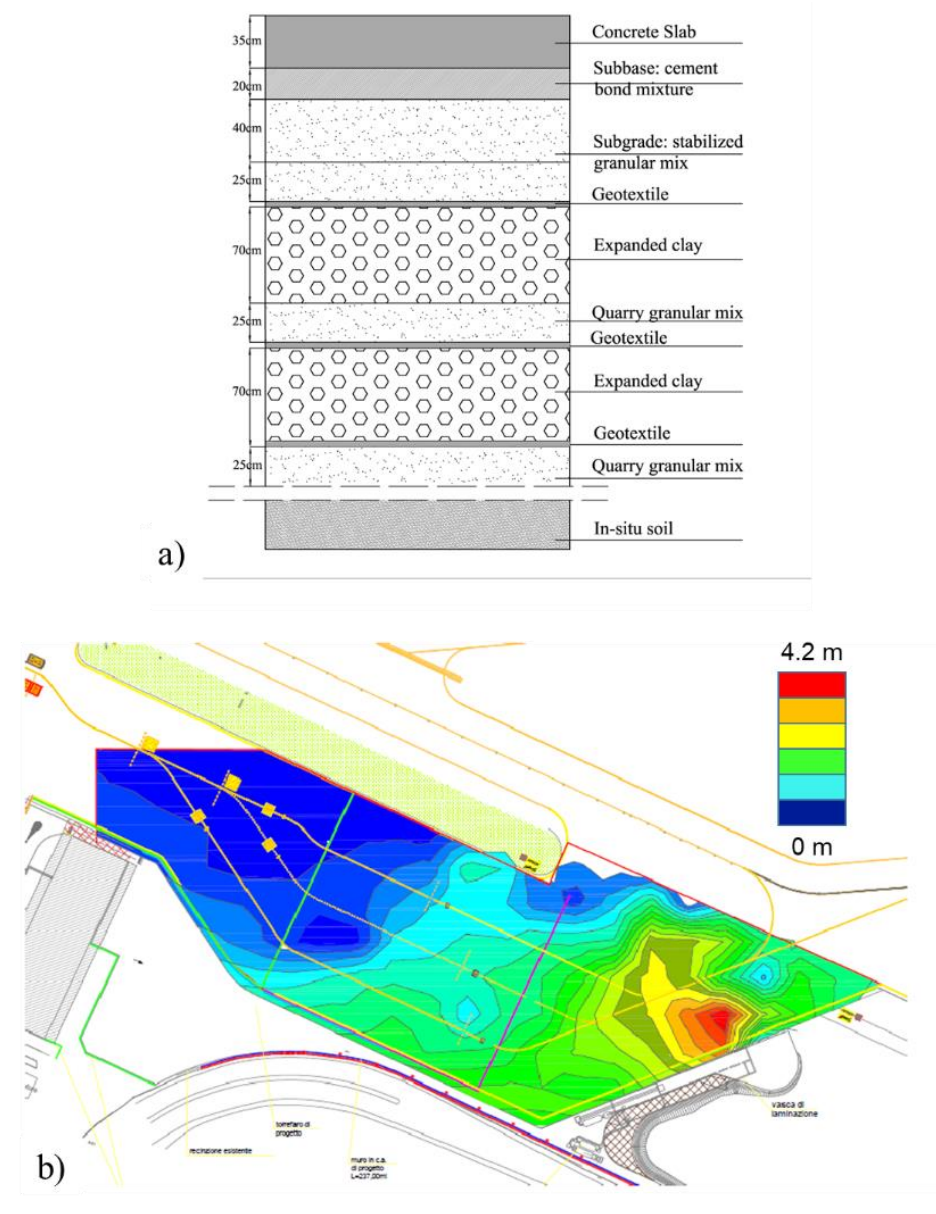

Figure 6. Intervention scenario 1: a) configuration of the light-clay embankment using the compensation technique; b) map of contour lines representing depth of excavations.

In more detail, a unique layer of lightweight expanded clay reaching the required height is considered in this case study (Fig.7(a)). This approach implies use of non-conventional methods for material compaction resulting in longer time required to complete the whole process. To avoid overstress at the shallower expanded clay layer, a single $30 \mathrm{~cm}$ layer of granular mix is placed between the subbase and the lightweight layer.

Following the methodology pursued in scenario 1, it was possible to calculate the depth of excavations of on-site material for compensation of the overload from embankments. As the granular mix layers are here replaced by lightweight filling materials, the overload are found to be lower than the first scenario. This turns out to give a lower amount of excavations. In more detail, average and maximum depths of the excavations were found to be $2.0 \mathrm{~m}$ and $3.6 \mathrm{~m}$, respectively (Fig. 7(b)). This turned out to give a reduction of required volumes of lightweight filling materials of $26 \%$ with respect to scenario 1 . 

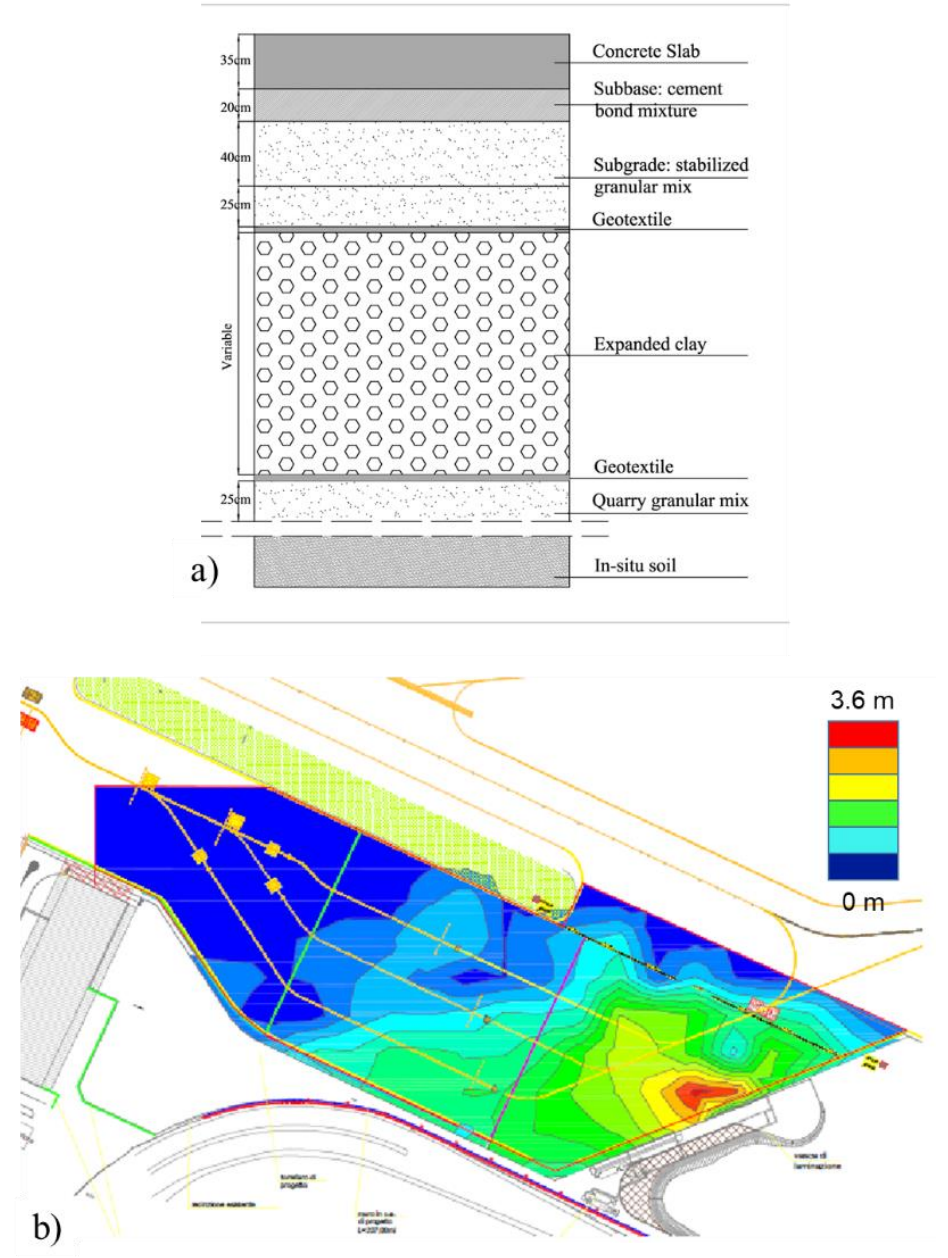

Figure 7. Intervention scenario 2: a) configuration of the light-clay embankment using the compensation technique; b) map of contour lines representing depth of excavations.

\section{CONCLUSIONS AND FUTURE DEVELOPMENTS}

This research reports a multi-stage design approach for construction of a 29.000- $\mathrm{m}^{2}$ deicing station in a critical soil site located at the International Airport "Guglielmo Marconi" in Bologna, Italy. The main aim of the project was to identify sustainable interventions to avoid short- and long-term economic, environmental and operational issues.

An assessment based on the use of fundamental geotechnical parameters was first implemented to create thematic maps of the construction design area, followed by a comparative analysis of potential intervention scenarios. 
A combination of lightweight filling and advanced materials has been proposed to ensure suitable homogeneity and bearing capacity of the laying ground. The lightweight filling materials were used for realization of the designed embankments as well as for replacement of the excavated in situ soil. This allowed to compensate the overload exerted by the embankments on the laying ground.

Future research could task itself on a comparative investigation of various compaction methodologies to be used for laying out the lightweight expanded clay layers.

\section{ACKNOWLEDGEMENTS}

The authors are grateful to Mr. Giuseppe Triassi for the contribution given to data collection. The authors would also like to express their gratitude to Mr. Domenico Terra (Aeroporto di Bologna S.p.A.) for the organisation of the preliminary surveys.

\section{REFERENCES}

Barends, F.B.J. (2011). "Introduction to soft soil geotechnique”, Ios Press.

Budhu, M. (2010). "Soil Mechanics and Foundation - 3rd Edition", John Wiley \& Sons Inc.

Delatte, N.J. (2014). "Concrete Pavement Design, Construction, and Performance", CRC Press.

Federal Aviation Administration (FAA), (2013). "Design of Aircraft Deicing Facilities”, Advisory Circular. 150/5300-14C.

Federal Aviation Administration (FAA), (2016). "Airport Pavement Design and Evaluation”, Advisory Circular, AC 150/5320-6F.

Federal Aviation Administration (FAA), (2017). "Airport Field Condition Assessments and Winter Operations Safety", Advisory Circular. AC 150/520030D.

Federal Highway Administration (FHWA), (2009). "Computer-Based Guidelines for Concrete Pavements: HIPERPAV ® III USER MANUAL”, Publication no. FHWA-HRT-09-048.

Italian Civil Aviation Authority (ENAC), (2017)."Traffic data 2017".

Marradi, A., Pinori U., and Betti, G. (2012). "The Use of lightweight materials in road embankment construction", SIIV-5th International Congress-Sustainability of Road Infrastructures. 
Servizio Meteorologico dell'Aeronautica Militare, (2010). “Tabelle climatiche 19712000 della stazione meteorologica di Bologna Borgo Panigale dall'Atlante Climatico 1971-2000".

Vaslestad, J., Johansen, T.H., and Holm, W. (1993). "Load reduction on rigid culverts beneath high fills: long-term behaviour", Transportation Research Record, $1415,56-68$.

Yoder, E. J. and Witczak, M. W. (1975). "Principles of Pavement Design”, John Wiley \& Sons Ed. 